\title{
A new correction technique for measuring respiratory impedance through an endotracheal tube
}

\author{
A.M. Lorino, L. Beydon, C. Mariette, E. Dahan, H. Lorino
}

\begin{abstract}
A new correction technique for measuring respiratory impedance through an endotracheal tube. A.M. Lorino, L. Beydon, C. Mariette, E. Dahan, H. Lorino. @ERS Journals Ltd 1996.

ABSTRACT: Measurement of respiratory impedance (Zrs) in intubated patients requires corrections for flow-dependent resistance and air compression inside the endotracheal tube (ET). The purpose of this study was to test a new correction technique for these effects.

We therefore studied 110 patients in two conditions: breathing normally (C1), or breathing through an ET placed at the mouth (C2). In C1, we measured pressure and flow signals at the mouth, and in $\mathrm{C2}$, at the ET inlet, during application of a pseudorandom forced excitation $(4-32 \mathrm{~Hz})$. In $\mathrm{C} 1$, respiratory impedance was calculated directly as $Z$ 1. In C2, pressure data were first corrected for the flow-dependent resistance of the ET, and respiratory impedance was then corrected both for gas compression inside the set-up and ET inertance (impedance $Z_{2}$ ).

Strong linear relationships were found between the reference and corrected estimates of the resistance at $6 \mathrm{~Hz}$, the frequency dependence of resistance and the resonant frequency. The mean normalized distance between $Z_{1}$ and $Z_{2}$ observed in the patients over the 4-32 $\mathrm{Hz}$ frequency range was about $14 \%$ for resistance and $12 \%$ for reactance $(-9 \%$ and $-4 \%$, respectively, when considering the algebraic value of the distance). This slight underestimation of both components of impedance might be due to an overcorrection of pressure for the flow-dependent resistance of the ET.

We conclude that, in intubated patients, newly tested corrections for the mechanical contribution of the endotracheal tube may yield a fair estimate of respiratory impedance when pressure is measured at the inlet of the endotracheal tube.

Eur Respir J., 1996, 9, 1079-1086.
\end{abstract}

INSERM U296, Service de Physiologie et Département d'Anesthésie-Réanimation, Hôpital Henri Mondor, Créteil, France.

Correspondence: H. Lorino

Service d'Explorations Fonctionnelles Hôpital Henri Mondor

94010 Créteil

France

Keywords: Endotracheal tube forced oscillation input impedance

nonlinear resistance pseudorandom noise

Received: November 291994 Accepted after revision January 271996
To monitor respiratory mechanics of intubated patients in intensive care units, it is highly desirable to use a measurement technique which requires no special cooperation from the patient. The forced oscillation technique (FOT) allows the estimation of respiratory impedance (Zrs) by simply applying a pseudorandom airflow excitation at the airway opening of the patient. This method of $\mathrm{Zrs}$ measurement is based on the assumption that the mechanical behaviour of the respiratory system remains fairly linear within the flow amplitude range of the forced oscillations applied. In this respect, the presence of an endotracheal tube (ET), which introduces a nonlinear resistive component [1], makes it problematical to measure $Z_{\mathrm{rs}}$ by the standard FOT, i.e. with proximal pressure and flow recorded at the ET inlet.

The effects of the nonlinearities due to the flow-dependent component of the ET resistance can be limited by measuring $Z_{\text {rs }}$ during periods of apnoea obtained after either hyperventilation or curarization [2-5]. However, from an ethical point of view, it is not always possible to obtain periods of apnoea in spontaneously breathing patients. Theoretically, the effect of the flow-dependent ET resistance could be totally removed by measuring a distal pressure $[6,7]$, either by using a special and rather expensive ET incorporating a lumen with an opening near the distal end $[5,7]$, or by introducing a catheter into a standard ET [8]. Whatever the technique chosen to measure pressure, data corrections are still needed to obtain the true $Z_{r s}$ value. When proximal pressure is recorded, these corrections account for the shunt and serial ET impedance $[3,9,10]$, and when distal pressure is recorded, for the ET transfer function [7].

The objective of this study was to investigate whether the forced oscillation technique could be made more easily applicable to patients intubated with standard ETs, by eliminating the need to interrupt spontaneous breathing and to record distal pressure. For this purpose, a newly developed correction technique was implemented, which allowed the mechanical effects due to the presence of the ET, i.e. nonlinear resistance of the ET, gas compression occurring between the transducers and the ET outlet, and ET inertance, to be eliminated. The effectiveness of these corrections was then checked by studying a group of 110 patients breathing either normally or through an ET placed at the mouth to simulate intubation. 


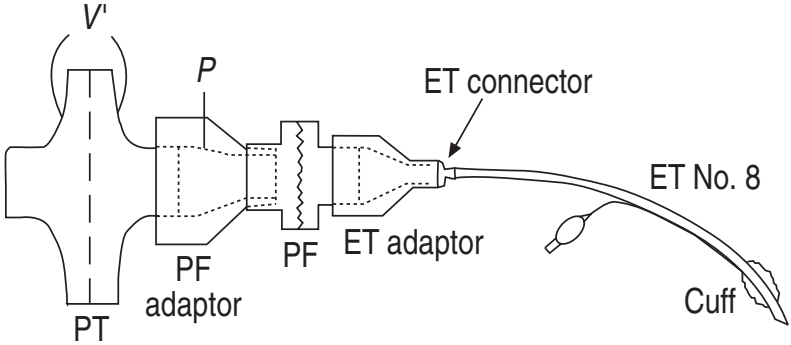

Fig. 1. - Experimental set-up for measurement of respiratory impedance in patients breathing through the ET. PT: pneumotachograph; $\mathrm{PF}$ : protect filter; $V^{\prime}$ : flow transducer; $P$ : pressure transducer; ET: endotracheal tube (internal diameter (ID) $8 \mathrm{~mm}$ ). To measure reference impedance, the ET and its adaptor were removed from this set-up.

\section{Materials and methods}

\section{Impedance measurement}

Respiratory impedance was measured by the FOT as described previously [11], with the subjects sitting, wearing a noseclip, and supporting their cheeks with their hands. The forced pseudorandom excitation applied at the mouth was composed of 29 harmonics (4-32 Hz) of the fundamental $(1 \mathrm{~Hz})$, with enhanced amplitudes at the lower frequencies to limit the effect of spontaneous breathing. The phases were calculated in order to minimize the peak-to-peak amplitude of the excitation signal. The forced signal, generated by a digital-to-analogue converter, excited, through a power amplifier, two $60 \mathrm{~W}$ loudspeakers attached to a $12 \mathrm{~L}$ rigid chamber. The amplitude of the resulting pressure oscillations was limited to $2 \mathrm{hPa}$ peak-to-peak, which resulted in peak-to-peak flow amplitudes of $0.2-0.5 \mathrm{~L} \cdot \mathrm{s}^{-1}$. A $0.25 \mathrm{~L} \cdot \mathrm{s}^{-1}$ bias flow prevented rebreathing, and a side tube open to the atmosphere allowed the passage of the low-frequency components of spontaneous ventilation. Pressure $(P)$ was measured by a differential pressure transducer (Sensym SCX 01D, \pm 70 $\mathrm{hPa}$ ), and flow $\left(V^{\prime}\right)$, by a screen pneumotachograph (Jaeger Lilly; resistance $\left.=0.35 \mathrm{hPa} \cdot \mathrm{L}^{-1} \cdot \mathrm{s}\right)$ connected to a similar transducer (fig. 1). Pressure and flow signals were lowpass filtered (Butterworth; 8th order, cut-off frequency $=32 \mathrm{~Hz}$ ), and sampled at $128 \mathrm{~Hz}$ for $16 \mathrm{~s}$. When breathing was performed through the ET, pressure was corrected for the pressure drop across the ET, as described below. Finally, flow and pressure were high-pass filtered $(3 \mathrm{rd}$ order, cut-off frequency $=3.5 \mathrm{~Hz}$ ) to eliminate the low harmonics of the breathing noise.

Using a Fast Fourier Transform (FFT) algorithm, spectral analysis was applied to adjacent $4 \mathrm{~s}$ periods [12], and the spectra yielded by three $16 \mathrm{~s}$ manoeuvres were averaged. Impedance data were calculated as the complex ratio of the auto-spectrum of $P$ to the cross-spectrum of $P$ and $V^{\prime}: Z=R+\mathrm{j} \cdot X$ (with $\mathrm{j}^{2}=-1$ ), where the real part $(R)$ is called resistance, and the imaginary part $(X)$ is called reactance.

Impedance data were only retained for analysis at the frequencies $(f)$ where the coherence function $\left(\gamma^{2}(f)\right)$ was higher than 0.9 [11]. Resistance was submitted to linear regression analysis between 4 and $16 \mathrm{~Hz}$, according to the equation:

$$
R=R 0+\mathrm{S} \cdot f
$$

where the slope $(S)$ describes the frequency dependence of resistance. The resistance at $6 \mathrm{~Hz}(R(6))$ was taken as an index characterizing the degree of obstructive disease. Resonant frequency $\left(f_{r}\right)$ was defined as the frequency at which reactance was zero.

\section{Endotracheal tube}

The mechanical features of the set-up incorporating a standard ET (Mallinckrodt, internal diameter (ID) $=8$ $\mathrm{mm}$ ) were determined as explained in Appendix A. Briefly, the Rohrer coefficients $(K 1$ and $K 2)$ of the flowdependent resistance of the ET $\left(K 1+K 2 \mid V^{\prime}\right)$ were measured in the course of constant flow and sinusoidal experiments [13]. The apparent impedance of the isolated ET (ZET) was measured by the FOT, and the ET inertance (IET) was calculated by applying linear regression analysis to the imaginary part of ZET. The occlusion impedance (Zoc) was measured on the occluded ET by the FOT [14, $15]$. As stated previously $[13,16]$, this Zoc accounts both for the shunt gas compression in the measuring set-up, including the ET, and the dynamic asymmetry of the transducers [14].

\section{Patients}

We randomly selected 110 patients who came to our laboratory for lung function tests. These patients were fully informed of the experimental protocol and gave informed consent. They were studied in two conditions, in a random order: normally breathing $(\mathrm{C} 1)$, and breathing through the ET placed at the mouth (C2) (fig. 1). In both conditions, care was taken to maintain the head in the same position. The pressure and flow signals were measured on the pneumotachograph side of the protect filter inserted into the set-up (fig. 1), i.e., near the mouth in $\mathrm{C} 1$, and near the ET inlet in $\mathrm{C} 2$.

An additional group of 16 patients was also studied in a third condition (C3), with the ET inserted into the experimental set-up, but upstream of the point of flow and pressure measurement. Thus, in $\mathrm{C} 3$, respiratory impedance $\left(Z_{3}\right)$ was measured in the same way as in $\mathrm{C} 1$, but patients were submitted to the same respiratory load as in $\mathrm{C} 2$. In this particular study, $\mathrm{C} 1$ and $\mathrm{C} 3$ were successively taken as the reference condition.

\section{Correction algorithm}

In $\mathrm{C} 1$ and $\mathrm{C} 3$, reference respiratory impedance was directly calculated as $Z 1$ and $Z 3$. In $C 2$, pressure data were first corrected for the flow-dependent resistance of the ET $\left(K 1+K 2 \mid V^{\prime}\right)$, and impedance was calculated as $Z_{2}$ *. Next, $Z_{2}^{*}$ was corrected for gas compression inside the ET by using the Zoc impedance recorded previously [13-16]. The resulting impedance $Z 2^{* *}$ was calculated as:

$$
Z 2^{* *}=Z 2^{*} \cdot Z_{\mathrm{oc}} /\left(Z_{\mathrm{oc}}-Z_{2} *\right)
$$

Lastly, $Z 2^{* *}$ was corrected for the inertance of the ET, by subtracting $(2 \pi f \cdot I \mathrm{ET})$ from the imaginary part of $Z 2^{* *}$ $(4 \leq f \leq 32 \mathrm{~Hz})$. These corrections made it possible to obtain an estimate of the respiratory impedance referred to below as the corrected impedance $\mathrm{Z} 2$. 


\section{Data analysis}

Impedance data (corrected $Z 2$, and reference $Z=Z_{1}$ or Z3) were expressed as resistance $(R 2$, and $R=R 1$ or $R 3$ ) and as reactance $(X 2$, and $X=X 1$ or $X 3)$. The effectiveness of the correction algorithm was assessed by calculating for each frequency $(f)$ the relative distance $(\mathrm{D} R(f))$ between the reference resistance $R$ and the corrected resistance $R 2$ :

$$
\mathrm{D} R(f)=100 \cdot(R 2(f)-R(f)) /\left[\left(R(f)^{2}+X(f)^{2}\right)\right]^{1 / 2}
$$

and the relative distance $(\mathrm{D} X(f))$ between the reference reactance $X$ and the corrected reactance $X 2$ :

$$
\mathrm{D} X(f)=100 \cdot(X 2(f)-X(f)) /\left[\left(R(f)^{2}+X(f)^{2}\right)\right]^{1 / 2}
$$

For each patient, the following mean distances were calculated over the $4-32 \mathrm{~Hz}$ frequency range:

$$
\begin{aligned}
& \overline{\mathrm{D}} R=-\sum \mathrm{D} R(f) \\
& \text { n } f \\
& \overline{\mathrm{D}} R, \mathrm{abs}=\underset{\mathrm{n} f}{-\underset{\mathrm{D}}{-}}|\mathrm{\textrm {D } R}(f)| \\
& \overline{\mathrm{D}} X=-\Sigma \mathrm{D} x(f) \\
& \text { n } f \\
& \overline{\mathrm{D}} X, \mathrm{abs}=\frac{1}{\mathrm{n} f} \underset{\mathrm{D} X(f)}{\mathrm{n}}
\end{aligned}
$$

where $\mathrm{n}$ is the number of coherent data points $\left(\gamma^{2}(f) \geq 0.9\right)$ in the frequency range considered.

All the data obtained were analysed by Student's paired or unpaired t-test. The $R, \mathrm{~S}$ and $f_{\mathrm{r}}$ parameters were also analysed by linear regression.

\section{Results}

\section{Endotracheal tube}

The Rohrer coefficients of the ET resistance were estimated as $K 1=1 \pm 0.2 \mathrm{hPa} \cdot \mathrm{L}^{-1} \cdot \mathrm{s}$ and $K 2=5 \pm 0.3 \mathrm{hPa} \cdot \mathrm{L}^{-2} \cdot \mathrm{s}^{2}$, and the ET inertance was measured as $I E T=0.078 \pm 0.004$ $\mathrm{hPa} \cdot \mathrm{L}^{-1} \cdot \mathrm{s}^{2}$ (see Appendix A).

\section{Patients}

In the first group of 110 patients, the mean reference resistance at $6 \mathrm{~Hz}(R 1(6))$ ranged $1.5-10.9 \mathrm{hPa} \cdot \mathrm{L}^{-1} \cdot \mathrm{s}$, and the mean reference resonant frequency $\left(f_{\mathrm{r} 1}\right)$ ranged 5-31 $\mathrm{Hz}$. In the $\mathrm{C} 2$ condition, the peak-to-peak amplitude of the breathing flow was about $85 \pm 8 \%$ of that observed in C1.

The respective contributions of the successive correction steps $\left(K 1, K 2 ; Z_{\mathrm{oc}} ; \mathrm{IET}\right)$ are illustrated in figure 2 for a representative patient. The correction for the ET resistance affected resistive impedance only and appeared to be roughly independent of frequency. When the
$\mathrm{C} 1$ and $\mathrm{C} 2$ conditions were considered $(\mathrm{n}=110)$, the residual distances between reference and corrected impedances were about $\overline{\mathrm{D}} R=-9 \%$ and $\overline{\mathrm{D}} R$,abs $=14 \%$ for resistance, and about $\overline{\mathrm{D}} X=-4 \%$ and $\overline{\mathrm{D}} X$,abs $=12 \%$ for reactance (table 1$)$.

a)

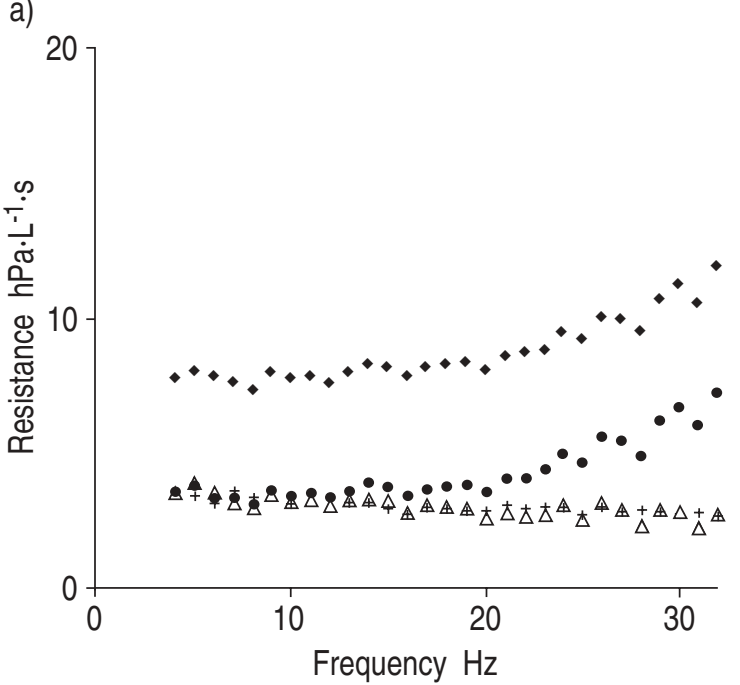

b)

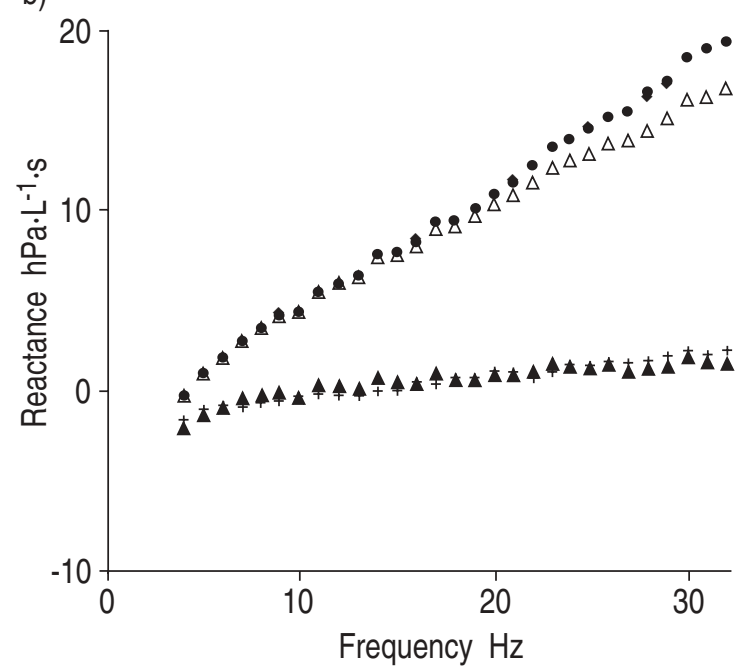

Fig. 2. - Illustration of the three successive steps of the correction scheme: +: reference impedance $(Z 1)$; : pseudo-impedance measured through the ET; $\bullet$ : impedance corrected for the ET resistive contribution (Step 1); $\Delta$ : impedance corrected for Zoc (Step 2); $\boldsymbol{\Delta}$ : reactance $(X)$ corrected for IET (Step 3). ET: endotracheal tube; Zoc: occlusion impedance; IET: inertance of the endotracheal tube.

Table 1. - Normalized distances between reference and corrected estimates of respiratory impedance

\begin{tabular}{lrrccc}
\hline Pts & $\mathrm{n}$ & \multicolumn{1}{c}{$\begin{array}{c}\overline{\mathrm{D}} R \\
\%\end{array}$} & $\begin{array}{c}\overline{\mathrm{D}} R \text {,abs } \\
\%\end{array}$ & $\begin{array}{c}\overline{\mathrm{D}} X \\
\%\end{array}$ & $\begin{array}{c}\overline{\mathrm{D}} X \text {,abs } \\
\%\end{array}$ \\
\hline (a) & 110 & $-9.3 \pm 10.5$ & $13.8 \pm 6.3$ & $-3.8 \pm 11.1$ & $12.4 \pm 5.8$ \\
(b) & 50 & $-10.2 \pm 10.6$ & $14.5 \pm 6.4$ & $-5.9 \pm 10.3$ & $12.8 \pm 4.9$ \\
(c) & 60 & $-8.5 \pm 10.5$ & $13.3 \pm 6.3$ & $-2.1 \pm 11.5$ & $12.1 \pm 6.4$ \\
\hline
\end{tabular}

Data are presented as mean \pm SD. (a): all patients; (b): patients with resistance at $6 \mathrm{~Hz} \leq 4 \mathrm{hPa} \cdot \mathrm{L}^{-1} \cdot \mathrm{s}$; (c): patients with resistance at $6 \mathrm{~Hz}>4 \mathrm{hPa} \cdot \mathrm{L}^{-1} \cdot \mathrm{s}$. $\overline{\mathrm{D}} R$ and $\overline{\mathrm{D}} R$,abs: algebraic and absolute distances between reference and corrected estimates of resistance; $\overline{\mathrm{D}} X$ and $\overline{\mathrm{D}} X$,abs: algebraic and absolute distances between reference and corrected estimates of reactance; Pts: patients. 
Table 2. - Frequency dependence of the normalized distances between reference $\left(Z_{1}\right)$ and corrected $\left(Z_{2}\right)$ impedances

\begin{tabular}{lcccc}
\hline$f$ & $\overline{\mathrm{D}} R$ & $\overline{\mathrm{D}} R, \mathrm{abs}$ & $\overline{\mathrm{D}} X$ & $\overline{\mathrm{D}} X, \mathrm{abs}$ \\
$\mathrm{Hz}$ & $\%$ & $\%$ & $\%$ & $\%$ \\
\hline $4-32$ & $-9.3 \pm 10.5$ & $13.8 \pm 6.3$ & $-3.8 \pm 11.1$ & $12.4 \pm 5.8$ \\
$4-16$ & $-10.8 \pm 12.5$ & $14.5 \pm 8.4$ & $1.2 \pm 8.4$ & $8.4 \pm 4.3$ \\
$17-32$ & $-8.1 \pm 10.7 *$ & $13.3 \pm 6.0$ & $-8.6 \pm 14.7 *$ & $15.5 \pm 8.9 *$
\end{tabular}

Data are presented as mean \pm SD in the 110 patients. For each patient the distances were averaged over the specified frequency range. $f:$ frequency. For further definitions see legend to table 1 . *: significantly different from the same distance calculated over $4-16 \mathrm{~Hz}(\mathrm{p}<0.01)$.

a)

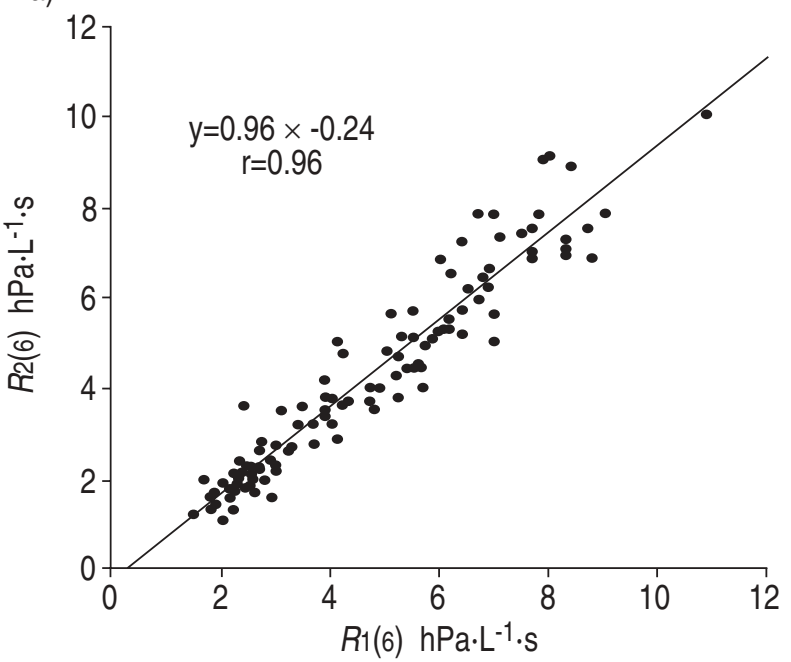

b)

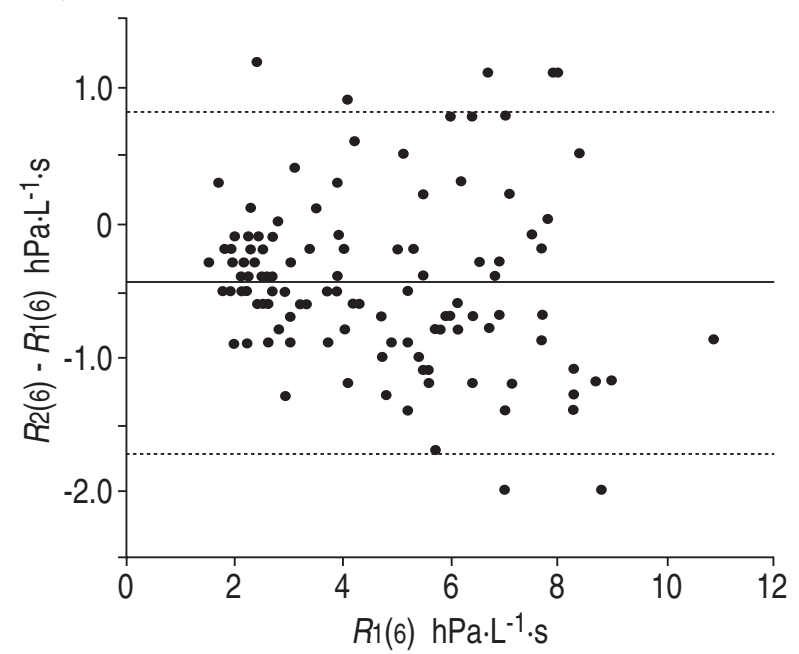

Fig. 3. - Reference $(R 1(6))$ and corrected $(R 2(6))$ estimates of resistance at $6 \mathrm{~Hz}$ are compared in the 110 subjects. a) $R 2(6))$ is plotted versus $R 1(6)$ ) (straight line: regression line); b) the difference $(R 2(6)$ $R 1(6))$ is plotted versus $R 1(6)$.

Although all these distances were significantly different from zero, there was no significant difference for any of them between the patients' subgroup with the lowest resistances $\left(R 1(6) \leq 4 \mathrm{hPa} \cdot \mathrm{L}^{-1} \cdot \mathrm{s} ; \mathrm{n}=50\right)$ and the remaining 60 patients. On the other hand, all of these distances but $\overline{\mathrm{D}} R$, abs appeared to be slightly frequency-dependent (table 2).
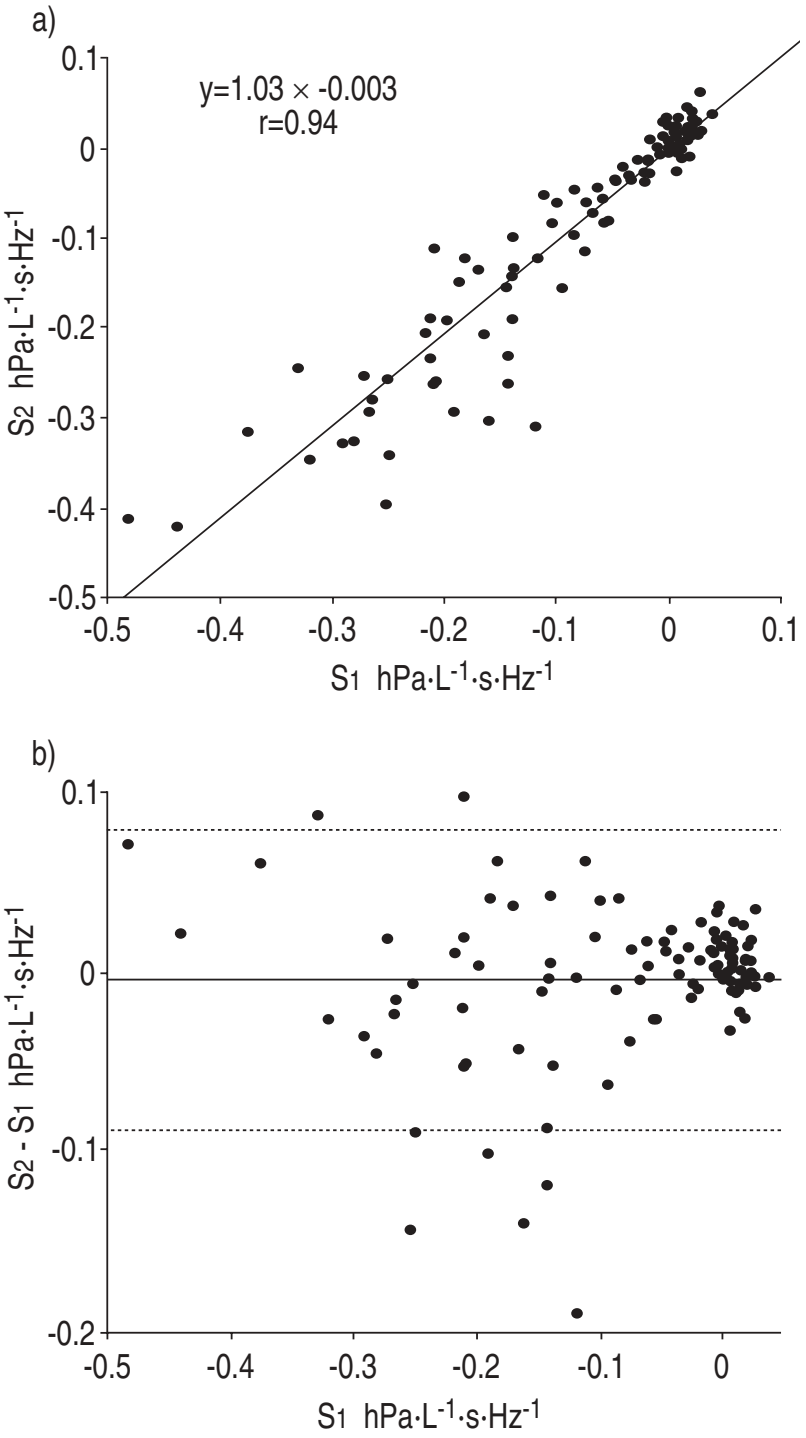

Fig. 4. - Reference (S1) and corrected (S2) estimates of the frequency dependence of resistance are compared in the 110 subjects: a) S2 is plotted versus S1 (straight line: regression line); b) the difference (S2$\mathrm{S} 1$ ) is plotted versus S1. S: slope, describes the frequency dependence of resistance.

The resistance at $6 \mathrm{~Hz}$, the slope of the resistance and the resonant frequency obtained after correction were found to be highly correlated with their respective reference values (figs. 3-5). The parameter $R 2(6)$ was slightly but significantly lower than its reference value $R 1$ (6) (4.2 \pm 2.2 vs $\left.4.6 \pm 2.2 \mathrm{hPa} \cdot \mathrm{L}^{-1} \cdot \mathrm{s} ; \mathrm{p}<0.001\right)$; whereas the slope $\mathrm{S}$ and the resonant frequency $f_{\mathrm{r}}$ were found to be similar in $\mathrm{C} 1$ and $\mathrm{C} 2(-0.085 \pm 0.125$ vs $-0.081 \pm 0.114$ $\mathrm{hPa} \cdot \mathrm{L}^{-1} \cdot \mathrm{s} \cdot \mathrm{Hz}^{-1}$ and $13.8 \pm 9.1$ vs $13.7 \pm 8.2 \mathrm{~Hz}$, respectively).

In the additional group of 16 patients, the mean resistance $R 1(6)$ ranged $1.6-8.7 \mathrm{hPa} \cdot \mathrm{L}^{-1} \cdot \mathrm{s}$ in $\mathrm{C} 1$, and $1.8-8.2$ $\mathrm{hPa} \cdot \mathrm{L}^{-1} \cdot \mathrm{s}$ in $\mathrm{C} 3$. There was no significant difference between the $\mathrm{C} 1$ and $\mathrm{C} 3$ reference conditions as regards the resistance at $6 \mathrm{~Hz}\left(R 1(6)=4.4 \pm 2.2 \mathrm{hPa} \cdot \mathrm{L}^{-1} \cdot \mathrm{s} v \mathrm{~s}\right.$ $\left.R 3(6)=4.7 \pm 2.1 \mathrm{hPa} \cdot \mathrm{L}^{-1} \cdot \mathrm{s}\right)$ and the slope $\mathrm{S}(\mathrm{S} 1=-0.101 \pm$ 0.135 vs $\left.\mathrm{S} 3=-0.121 \pm 0.167 \mathrm{hPa} \cdot \mathrm{L}^{-1} \cdot \mathrm{s} \cdot \mathrm{Hz}^{-1}\right)$, as well as the distances $\overline{\mathrm{D}} R$,abs $(10.9 \pm 6.0 \%$ in $\mathrm{C} 1$ vs $11.7 \pm 5.8 \%$ in $\mathrm{C} 3)$ and $\overline{\mathrm{D}} R(-4.3 \pm 10.3 \%$ in $\mathrm{C} 1$ vs $-8.2 \pm 9.2 \%$ in $\mathrm{C} 3)$. 
a)

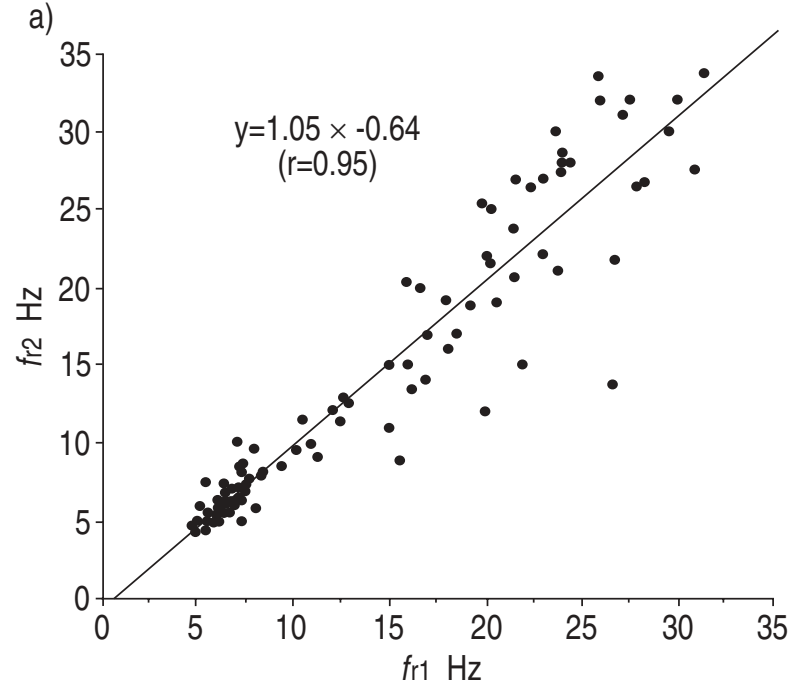

b)

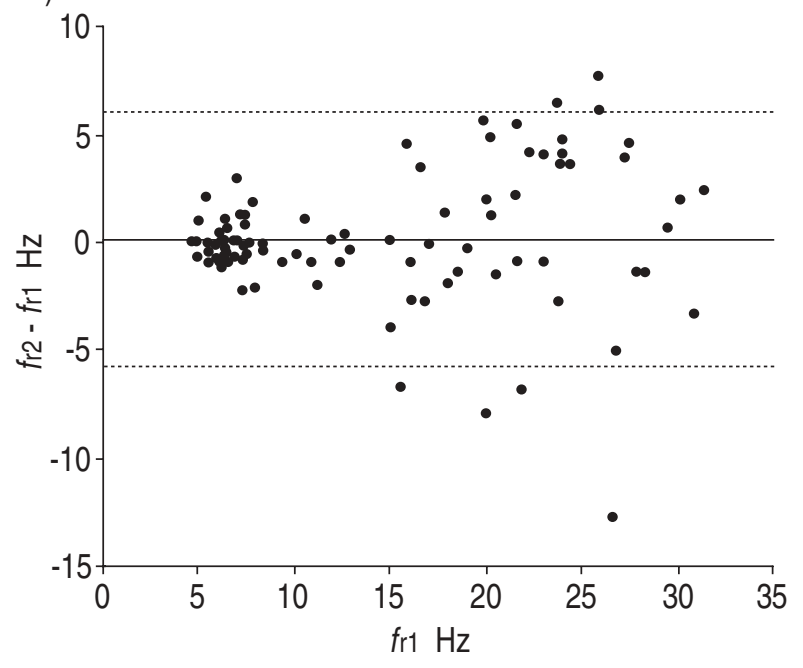

Fig. 5. - Reference $\left(f_{\mathrm{r} 1}\right)$ and corrected $\left(f_{\mathrm{r} 2}\right)$ estimates of resonant frequency are compared in the 110 subjects: a) $f_{\mathrm{r} 2}$ is plotted versus $f_{r 1}$ (straight line: regression line); $\left.b\right)$ the difference $(f r 2-f r 1)$ is plotted versus fr1.

\section{Discussion}

This study shows that our correction procedure allows $Z$ rs to be estimated by recording pressure and flow at the inlet of a standard ET in spontaneously breathing patients submitted to pseudorandom pressure excitation. Such a composite excitation allows short measurement periods, thus ensuring a good mechanical stability of the respiratory system during measurements [17] and a clinical applicability of FOT. In a previous study [13], we demonstrated in ventilated analogues that the correction of impedance data for ET resistance and shunt gas compression allowed the restoration of a fair estimate of resistive impedance in response to pseudorandom excitation. In the present investigation, the correction scheme was extended to reactance, and its reliability was evaluated in spontaneously breathing patients in whom intubation was simulated by inserting a standard cuffed ET into the mouthpiece.

As regards the isolated ET, our $K 1$ and $K 2$ values, as well as our estimate of IET, were in the range of those previously reported for ETs of the same calibre [3, 1820]. As expected, the correction for the ET resistance affected resistive impedance only (fig. 2). The fact that Zoc was all the more marked as frequency was higher, illustrates the important role of shunt gas compression and dynamic transducer asymmetry at high frequencies.

Distances between the corrected impedance and the reference impedance indicate a slight underestimation both of resistive impedance and reactance (table 1). An attractive explanation for the overcorrection of resistance would be changes in respiratory mechanics in response to the respiratory load induced by the ET [13]. Indeed, in obstructive patients, the ET external load might cause dynamic hyperinflation [21], which tends to reduce respiratory resistance. This assumption appeared in accordance with the fact that the $\overline{\mathrm{D}} R$ and $\overline{\mathrm{D}} R$, abs percentages were not related to the degree of pulmonary obstruction encountered, suggesting a loading effect related to the resistance level (table 1). Therefore, we studied an additional group of patients in a third condition (C3) allowing direct measurement of $\mathrm{Zrs}$ in the presence of the ET load. However, when comparing $\mathrm{C} 1$ to $\mathrm{C} 3$, no significant difference was observed for the $R(6)$ and $\mathrm{S}$ parameters or for the $\overline{\mathrm{D}} R$ and $\overline{\mathrm{D}} R$, abs distances. Thus, the underestimation of resistive impedance cannot be clearly attributed to respiratory loading effects, and other factors must be considered to explain this underestimation.

Among these factors, the $K 1$ and/or $K 2$ Rohrer parameters of the ET may have been somewhat overestimated through the in vitro experiments. It has indeed been suggested that the $K 1$ and $K 2$ values may vary, depending on whether the ET is isolated or not [22], and the flow is constant or oscillatory [19]. In this study, we determined the $K 1$ and $K 2$ coefficients in the isolated ET both through constant and oscillatory flow experiments. Between 4 and $10 \mathrm{~Hz}, K 1$ slightly increased, whereas $K 2$ decreased with frequency, which agrees with the findings of DoRkin et al. [23]. However, the mean $K 1$ and $K 2$ values that we obtained in constant and oscillatory flow experiments were very similar. In this connection, we previously observed that: 1) by correcting impedance data for the ET characteristics, the apparent resistive impedance of an intubated analogue was fairly corrected for flow dependence, whether the flow was purely oscillatory, or both oscillatory and ventilatory [13]; 2) whatever the type of flow, the apparent ET impedance was the same, whether the ET was isolated or connected to a resistive analogue (unpublished results). This latter observation is in accordance with the reports that the kinetic energy losses at the junction of the ET and a tube simulating the trachea only exert slight effects whether the flow is constant [24] or oscillatory [6]. Thus, our overcorrection of resistive impedance cannot be clearly attributed to inaccurate estimates of $K 1$ and $K 2$.

Another factor which might explain the difference between $Z_{1}$ and $Z_{2}$ is the order of the correction steps (correction for $K_{1}$ and $K 2$ in the time domain first, and then for Zoc in the frequency domain). Direct corrections for the apparent ET impedance in the frequency domain have already been proposed [3, 6, 25]. However, the ET resistance is flow-dependent, and the resulting pressure component affects the measured impedance in a way which makes corrections in the frequency domain difficult $[23,25]$. Indeed, when excitation flow includes 
integer multiples of a fundamental, complex combinations of these components occur in the frequency domain $[26,27]$. Furthermore, the corrections in the frequency domain are not applicable when flow includes both pseudorandom excitation and breathing signals [23]. Therefore, it appears that any correction for flow-dependent resistance should rather be made in the time domain, before computing impedance data.

Though the order of our successive corrections may remain open to criticism, it must be noted that, whatever the sequence of corrections steps adopted, one correction must be performed before others, and thus applies to partly corrected data. Only a single correction by a unique model including all the characteristics of the set-up would be theoretically appropriate, but, to our knowledge, such a model is not available. Another explanation of the overcorrection of impedance could be the flow distortion provoked by gas compression phenomena in the section separating the pneumotachograph from the patient. However, we previously observed a very satisfactory correction of the impedance of an intubated analogue ventilated by a breathing flow introduced on the same side of the pneumotachograph as the forced oscillations [13]. This observation tends to prove that gas compression phenomena are not likely to account for the overestimation of impedance.

As demonstrated in Appendix B, the tendency to underestimate $R$ and $X$ may rather be attributed to the fact that the correction term $\left(K_{2}\left|V^{\prime}\right| V^{\prime}\right)$ is an approximation of the actual flow-dependent pressure drop across the ET. The impedance underestimation is all the more marked as the breathing flow is higher than the oscillatory flow. Since the oscillatory flow tends to be lower when respiratory resistance increases, the underestimation of impedance may be expected to increase with pulmonary obstruction. This assumption is in accordance both with the significant linear relationship observed between $R 1(6)$ and $R 2(6)$, and the fact that the percentage distances $\overline{\mathrm{D}} R$ and $\overline{\mathrm{D}} R$,abs were not significantly different in the least and the most obstructive subgroup of patients. Moreover, it must be stressed that this slight underestimation did not affect the frequency dependence of resistive impedance, as illustrated by the similar $\mathrm{S}_{1}$ and $\mathrm{S} 2$ values.

As regards respiratory reactance, the underestimation of $X_{1}$ by $X_{2}$, which clearly increased with frequency, might also be explained, in part, by an artifactual effect of the protect filter. Indeed, the mechanical contribution of the protect filter to the measured impedance, which affects both Zoc and IET, was removed from corrected reactance $X 2$, but not from reference reactance $X 1$. However, it must be stressed that this slight underestimation did not affect the resonant frequency, as illustrated by the similar $f_{\mathrm{r} 1}$ and $f_{\mathrm{r} 2}$ values.

The most interesting results of this study are the strong correlations found between the corrected and reference values of $R(6), S$ and $f_{\mathrm{r}}$ (figs. 3-5). Indeed, they demonstrate that, despite a slight underestimation of respiratory impedance, our correction algorithm yields a correct evaluation of the mechanical parameters derived from respiratory impedance measured during simulated intubation.

In actual intubated patients, the ET eliminates a large fraction of the respiratory inertance which resides in the trachea [9], and it also suppresses upper airway impedance; this implies that it is difficult to take the patient himself as a reference. This is why we initiated this simulation study. However, the measurement of $\mathrm{Zrs}$ in intubated patients will perhaps raise other problems, in relation to more complex patterns of flow, or to mucus deposition which may somewhat modify the ET characteristics estimated for a clean tube. In other respects, without a special set-up allowing application of the FOT during mechanical ventilation $[10,28]$, it is necessary to disconnect the patient from the ventilator during each period of measurement [5, 9]. Nevertheless, it must be emphasized that our correction technique also applies to spontaneously breathing subjects. This is a major advantage compared to other proposed correction techniques which require periods of apnoea and, therefore, cannot be used during the weaning phase [18].

In conclusion, our original correction scheme allows satisfactory estimation of respiratory impedance in patients breathing through an endotracheal tube, whatever the level of their respiratory resistance. The choice of both pressure measurement at the endotracheal tube inlet and pseudorandom excitation should obviously facilitate the use of the forced oscillation technique in medical and surgical intensive care units, and allow monitoring of respiratory resistance in intubated patients. However, our correction method requires a further validation, which could be the comparison of corrected resistive impedance to respiratory resistance estimated by a reference technique, such as the occlusion technique.

\section{Appendix A: mechanical characteristics of the ET}

\section{ET resistance}

The Rohrer coefficients ( $K 1$ and $K 2)$ of the flow-dependent resistance of the ET $\left(K 1+K 2 \mid V^{\prime}\right)$ were measured in the course of constant flow $\left(0.2-0.8 \mathrm{~L} \cdot \mathrm{s}^{-1}\right)$ and sinusoidal experiments $(4-10 \mathrm{~Hz}$, with flow ranging $0.05-0.3$ $\left.\mathrm{L} \cdot \mathrm{s}^{-1}\right)$. The corresponding estimates of $K 1$ and $K 2$ were obtained by linear regression of $\left(P / V^{\prime}\right)$ over $V^{\prime}$ for the constant flows, and by linear regression of resistive impedance over $V^{\prime}$ amplitude for the sinusoidal flows (table $3)$. These estimates were found to be similar whether the ET was isolated or connected to a known analogue $(R=3.2$ $\left.\mathrm{hPa} \cdot \mathrm{L}^{-1} \cdot \mathrm{s}, I=0.003 \mathrm{hPa} \cdot \mathrm{L}^{-1} \cdot \mathrm{s}^{2}\right)$. When a breathing signal was superimposed on the sinusoidal oscillation, $K 1$ and $K 2$ tended to be less frequency-dependent (table 3 ). The mean values of the different estimates of $K 1$ and $K 2$ $\left(0.99 \pm 0.16\right.$ and $5.01 \pm 0.26 \mathrm{hPa} \cdot \mathrm{L}^{-2} \cdot \mathrm{s}^{2}$, respectively) were retained to characterize the ET resistance.

Table 3. - Values for the $\mathrm{K}_{1}$ and $\mathrm{K}_{2}$ Rohrer coefficients of the endotracheal tube

\begin{tabular}{lcc}
\hline Flow pattern & $\begin{array}{c}\mathrm{K} 1 \\
\mathrm{hPa} \cdot \mathrm{L}^{-1} \cdot \mathrm{s}\end{array}$ & $\begin{array}{c}\mathrm{K} 2 \\
\mathrm{hPa} \cdot \mathrm{L}^{-1} \cdot \mathrm{s}\end{array}$ \\
\hline Constant (ca) & $0.96 \pm 0.05$ & $4.89 \pm 0.19$ \\
Constant (vac) & $1.06 \pm 0.05$ & $5.19 \pm 0.17$ \\
Sinusoid $(4 \mathrm{~Hz})$ & $0.88 \pm 0.014$ & $5.18 \pm 0.20$ \\
Sinusoid $(4 \mathrm{~Hz})+$ br & $0.94 \pm 0.011$ & $5.11 \pm 0.18$ \\
Sinusoid $(10 \mathrm{~Hz})$ & $1.09 \pm 0.011$ & $4.78 \pm 0.23$ \\
Sinusoid $(10 \mathrm{~Hz})+$ br & $1.04 \pm 0.009$ & $4.89 \pm 0.20$ \\
\hline
\end{tabular}

Data are presented as mean \pm SD for constant flows, generated by either compressed air (ca) or vacuum (vac), and sinusoidal flows at 4 and $10 \mathrm{~Hz}$. br: quiet breathing signal was added to the sinusoidal oscillation. 

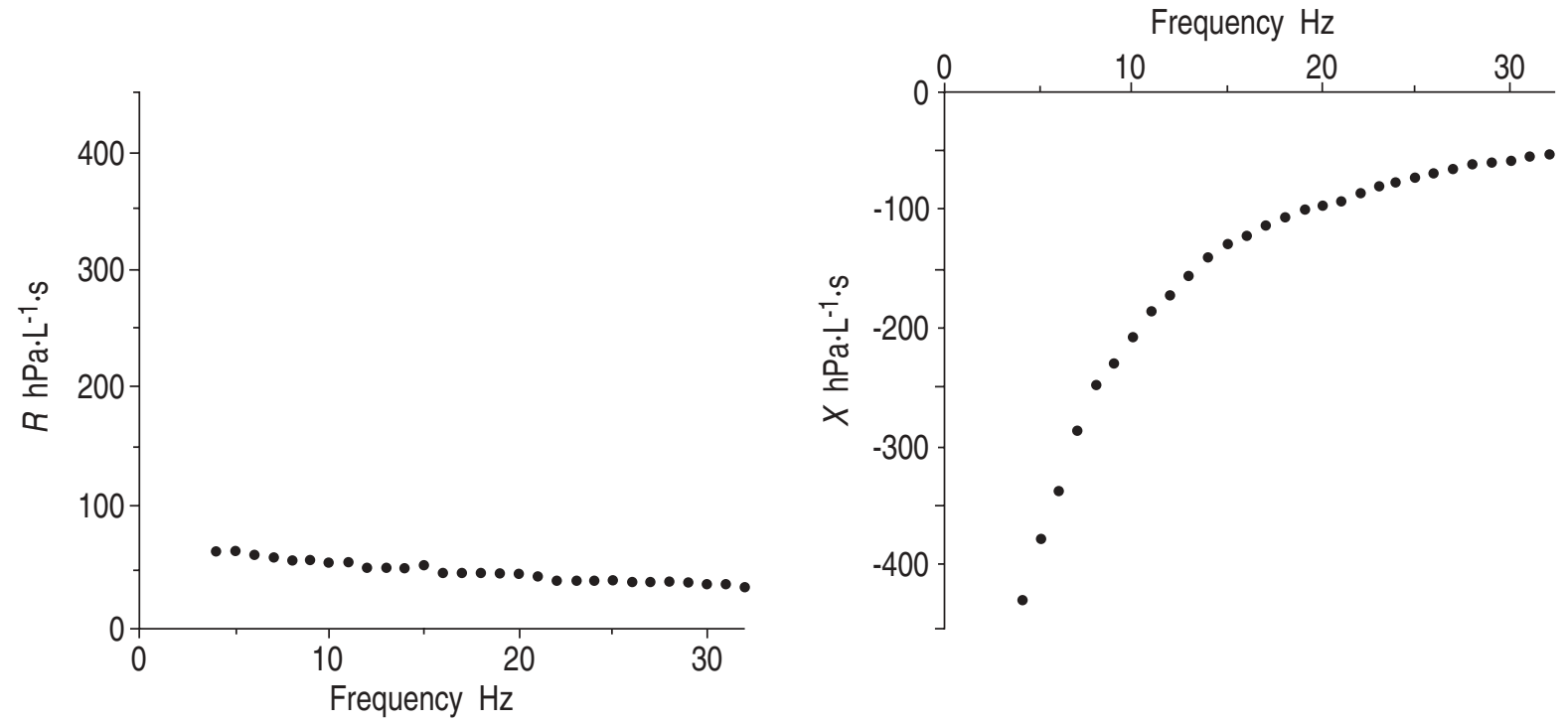

Fig. 6. - Impedance of the occluded ET $(Z o c)$ measured by the forced oscillation technique. $R$ : resistance, real part of Zoc; $X$ : reactance, imaginary part of Zoc.

\section{Occlusion impedance}

The impedance $(Z o c)$ of the occluded set-up, ET included, was evaluated for the transducer arrangement used in this study and was found to be highly reproducible. As expected, the imaginary part of Zoc, which accounts for the compression phenomena occurring between the transducers and the occlusion site, looked like a pure compliance (fig. 6). On the other hand, the real part of Zoc, which accounts for the characteristics of the pressure transducers and their connecting tubes, proved to be highly dependent on the features of the experimental set-up. For example, reversing the transducers yielded a real part of Zoc increasing with frequency. The Zoc estimate corresponding to the set-up of this study (fig. 6) has proved to accurately correct impedance of physical analogues measured with the same set-up [13].

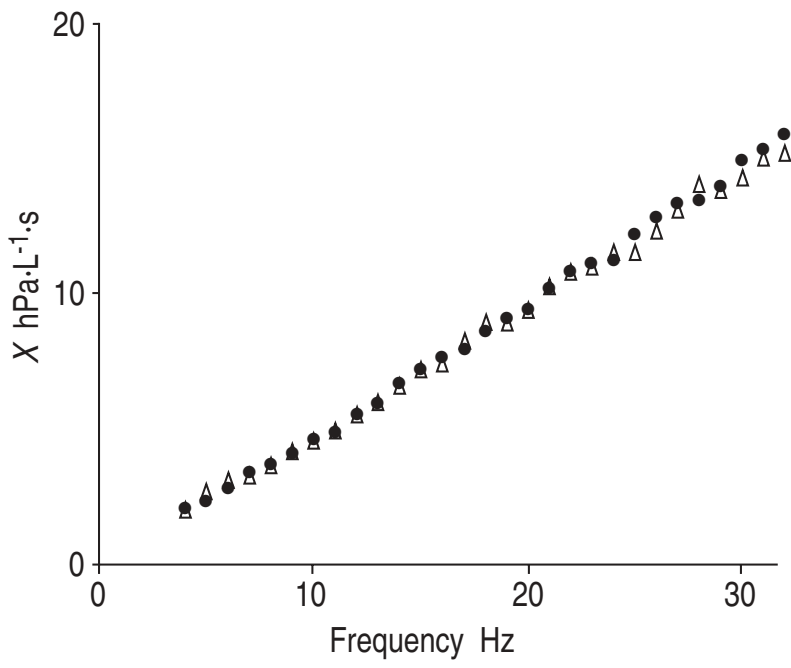

Fig. 7. - Imaginary part $(X)$ of the ET impedance (ZET), plotted as a function of frequency. These typical measurements $(\Delta$ and $\bullet)$ were obtained with an additive breathing flow.

\section{ET inertance}

The impedance of the ET (ZET) was measured in two conditions: with or without a breathing flow introduced on the loudspeaker side of the pneumotachograph. The ET inertance (IET) was calculated by linear regression analysis of the imaginary part of ZET on $\omega$, with $\omega=2 \pi \cdot f$ ( $f=$ frequency). Addition of a breathing flow yielded a slightly lower estimate of the ET inertance (IET $=0.078 \pm$ $\left.0.004 \mathrm{hPa} \cdot \mathrm{L}^{-1} \cdot \mathrm{s}^{2}\right)$ which was retained for the study in breathing patients (fig. 7).

\section{Appendix B: pressure drop across the ET}

In the FOT, measured flow $\left(V^{\prime}\right)$ is the sum of two components:

$$
V^{\prime}=V^{\prime} \text { fo }+V^{\prime} \text { br }
$$

where $V^{\prime}$ fo is the forced oscillatory flow which acts on the protect filter, the ET, if present, and the patient impedance, while $V^{\prime}$ br is the breathing flow acting on the loudspeakers and side tube.

In condition $\mathrm{C} 2$, the ET resistance depends on the total flow:

$$
R \mathrm{ET}=K 1+K 2 \mid V^{\prime} \text { fo }+V^{\prime} \text { br } \mid
$$

The resulting pressure drop $(\Delta P)$ across the ET may then be expressed as:

$$
\Delta P \mathrm{ET}=R \mathrm{ET} \cdot V^{\prime} \text { fo }=\left(K 1+K 2 \mid V^{\prime} \text { fo }+V^{\prime} \mathrm{br} \mid\right) V^{\prime} \text { fo }
$$

The lumped correction applied in our study was:

$$
\left(K 1+K 2\left|V^{\prime}\right|\right) V^{\prime}=\left(K 1+K 2 \mid V^{\prime} \text { fo }+V^{\prime} \text { br } \mid\right)\left(V^{\prime} \text { fo }+V^{\prime} \text { br }\right)(12)
$$

We checked the effect of the supplementary corrective term $\left(K 1+K 2 \mid V^{\prime}\right.$ fo $+V^{\prime}$ br $\left.\mid\right) V^{\prime}$ br included in Equation (12) by performing a numerical simulation. Breathing flow was synthetized as the sum of three sinusoids with 
Table 4. - Influence of the relative amplitudes of the ventilatory and oscillatory flows on impedance estimation

\begin{tabular}{lcccc}
\hline $\mathrm{r}$ & \multicolumn{2}{c}{$\overline{\mathrm{D} R}$} & $\%$ & \multicolumn{2}{c}{$\overline{\mathrm{D} X}$} & $\%$ \\
& $4-16 \mathrm{~Hz}$ & $17-32 \mathrm{~Hz}$ & $4-16 \mathrm{~Hz}$ & $17-32 \mathrm{~Hz}$ \\
\hline 3 & -13.9 & -7.6 & -1.7 & -3.8 \\
2 & -9.1 & -5.0 & -1.1 & -2.5 \\
1 & -4.0 & -2.3 & -0.5 & -1.0 \\
\hline
\end{tabular}

r: ratio of the peak-to-peak amplitudes of the simulated ventilatory flow to the oscillatory flow measured in an analogue; $\overline{\mathrm{D}} R$ : algebraic distance between reference and corrected estimates of resistance; $\overline{\mathrm{D}} X$ : algebraic distance between reference and corrected estimates of reactance. These distances were calculated over the 4-16 and $17-32 \mathrm{~Hz}$ frequency ranges.

different frequencies, phases and amplitudes (fundamental: $0.1-0.25 \mathrm{~Hz}$ ), and combined with forced oscillation data registered in various analogues made of a resistance $(R)$, an inertance $(I)$ and a compliance $(C)$ associated in series.

Whereas, as expected, the component $\left(K 1 \cdot V^{\prime}\right.$ br $)$ was eliminated by high-pass filtering, the component ( $K 2$ $\mid V^{\prime}$ fo $+V^{\prime}$ br $\left.\mid\right) V^{\prime}$ br led to an underestimation of actual impedance by $R 2$ and $X 2$. Underestimation of $R 2$ decreased, whereas underestimation of $X 2$ tended to increase, with the FOT frequency $(f)$. Both errors increased with the ratio of the peak-to-peak amplitudes of $V^{\prime}$ br and $V^{\prime}$ fo, and showed little sensitivity to the frequency and phase characteristics of $V^{\prime}$ 'br. Typical results are presented in table 4 as a function of the ratio between the amplitudes of $V^{\prime}$ br and $V^{\prime}$ fo (characteristics of the analogue: $R=5.7$ $\left.\mathrm{hPa} \cdot \mathrm{s} \cdot \mathrm{L}^{-1}, I=0.019 \mathrm{hPa} \cdot \mathrm{L}^{-1} \cdot \mathrm{s}^{2}, C=0.030 \mathrm{~L} \cdot \mathrm{hPa}^{-1}\right)$.

Acknowledgement: The authors are grateful to R. Peslin for his constructive suggestions.

\section{References}

1. Orkin L, Siegel M, Rovenstine E. Resistance to breathing by apparatus used in anesthesia. Anesth Analg Curr Res 1954; 33: 217-233.

2. Bates JHT, Daroczy B, Hantos Z. A comparison of interrupter and forced oscillation measurements of respiratory resistance in the dog. J Appl Physiol 1992; 72: 46-52.

3. Fullton JM, Hayes DA, Pimmel RL. Pulmonary impedance in dogs measured by forced random noise with a retrograde catheter. J Appl Physiol: Respirat Environ Exercise Physiol 1982; 52: 725-733.

4. Tsai MJ, Pimmel RL, Stiff EJ, Bromberg PA, Hamlin RL. Respiratory parameter estimation using forced oscillatory impedance data. J Appl Physiol: Respirat Environ Exercise Physiol 1977; 43: 322-330.

5. Navajas D, Farré R, Canet J, Rotger M, Sanchis J. Respiratory input impedance in anesthetized paralyzed patients. J Appl Physiol 1990; 69: 1372-1379.

6. Michels A, Landser FJ, Cauberghs M, Van de Woestijne KP. Measurement of total respiratory impedance via the endotracheal tube: a model study. Bull Eur Physiopathol Respir 1986; 22: 615-620.

7. Navajas D, Farré R, Rotger M, Canet J. Recording pressure at the distal end of the endotracheal tube to measure respiratory impedance. Eur Respir J 1988; 2: 178-184.

8. Oostveen E, Inee C, Le Feber J, Bruining MA. Tip manometry beyond the endotracheal tube to measure respiratory impedance. Eur Respir Rev 1994; 4: 227-231.
9. Dorkin HL, Stark AR, Werthammer JW, Strieder DJ, Fredberg JJ, Frantz ID. Respiratory system impedance from 4 to $40 \mathrm{~Hz}$ in paralyzed intubated infants with respiratory disease. J Clin Invest 1983; 72: 903-910.

10. Peslin R, Da Silva JF, Duvivier C, Chabot F. Respiratory mechanics studied by forced oscillations during artificial ventilation. Eur Respir J 1993; 6: 772-784.

11. Lorino H, Mariette C, Karouia M, Lorino AM. Influence of signal processing on estimation of respiratory impedance. J Appl Physiol 1993; 74: 215-223.

12. Michaelson ED, Grassman ED, Peters WR. Pulmonary mechanics by spectral analysis of forced random noise. J Clin Invest 1975; 56: 1210-1230.

13. Lorino H, Lorino AM, Mariette C, Beydon L. Measurement of resistive impedance through an endotracheal tube. Eur Respir Rev 1994; 4: 220-226.

14. Farré R, Navajas D, Peslin R, Rotger M, Duvivier C. A correction procedure for the asymmetry of differential pressure transducers in respiratory impedance measurements. IEEE Trans Biomed Eng 1989; 36: 1137-1140.

15. Lorino H, Mariette C, Louis B, Lorino AM, Harf A. Respiratory impedance up to $250 \mathrm{~Hz}$ : influence of the characteristics of the pressure and flow transducers. Eur Respir Rev 1991; 1: 151-157.

16. Farré R, Peslin R, Oostveen E, Suki B, Duvivier C, Navajas D. Human respiratory impedance from 8 to 256 $\mathrm{Hz}$ corrected for upper airway shunt. J Appl Physiol 1989; 67: 1973-1981.

17. Van de Woestijne. The forced oscillation technique in intubated, mechanically-ventilated patients. Eur Respir J 1993; 6: 767-769.

18. Delavault E, Saumon G, Georges R. Nonlinear fluid systems identified by random noise inputs. J Appl Physiol: Respirat Environ Exercise Physiol 1982; 53: 1643-1649.

19. Sullivan M, Paliotta J, Saklad M. Endotracheal tube as a factor in measurement of respiratory mechanics. $J$ Appl Physiol 1976; 41: 590-592.

20. Lorino AM, Benhamou D, Lorino H, Harf A. A computerized method for measuring respiratory mechanics during mechanical ventilation. Bull Eur Physiopathol Respir 1986; 22: 81-84.

21. Marini JJ. Should PEEP be used in airflow obstruction? Am Rev Respir Dis 1989; 140: 1-3.

22. Chang HK, Mortola JP. Fluid dynamic factors in tracheal pressure measurement. J Appl Physiol 1981; 51: 218-225.

23. Dorkin HL, Jackson AC, Strieder DJ, Dawson SV. Interaction of oscillatory and unidirectional flows in straight tubes and an airway cast. J Appl Physiol 1982; 52: 10971105.

24. Behrakis PK, Higgs BD, Baydur A, Zin WA, MilicEmili J. Respiratory mechanics during halothane anesthesia and anesthesia-paralysis in humans. $J$ Appl Physiol: Respirat Environ Exercise Physiol 1983; 55: 1085-1092.

25. Delavault E, Saumon G. Fourier analysis of nonlinear fluid systems. IEEE Trans Biomed Eng 1982; 29: 215219.

26. Maki BE. Interpretation of the coherence function when using pseudorandom inputs to identify nonlinear systems. IEEE Trans Biomed Eng 1986; 33: 775-779.

27. Maki BE. Addendum to "Interpretation of the coherence function when using pseudorandom inputs to identify nonlinear systems". IEEE Trans Biomed Eng 1988; 35: 279-280.

28. Navajas D, Farré R, Rotger M, Torres A. Monitoring respiratory impedance by forced oscillation in mechanically-ventilated patients. Eur Respir Rev 1994; 4: 216-218. 